\title{
Effects of a nurse-led multicomponent intervention for frail older adults living alone in a community: a quasi-experimental study
}

Mi Sook Song and Sunjoo Boo*

\begin{abstract}
Background: Given the rapid aging of the population in Korea, efforts to slow down or prevent frailty, to support the health of older adults, should be an important public health priority. This may allow them to continue living within the community by keeping their functional independence for as long as possible. This study aimed to evaluate the nurse-led multicomponent intervention for community-dwelling pre-frail or frail elderly on physical and psychosocial outcomes.
\end{abstract}

Method: A non-equivalent control pre-, post-, and follow-up test design was used with a sample of 126 prefrail or frail older adults (62 in the experimental and 64 in the control group). The 12-week multicomponent intervention for the experimental group comprised physical exercise, cognitive training, and nutrition and disease management education. Outcome variables (Timed Up and Go Test results and measures of frailty, handgrip strength, depression, social activity, and social support) were measured both pre- and post-intervention, and after the 12-week follow-up period.

Results: For each group, we assessed the significant interaction of time with frailty, depression, social activity, and social support, as well as Timed Up and Go Test results. In the experimental group, levels of depression decreased while levels of social support and social activity increased from each measurement period to the next, within the 12-month study period; those in the control group were relatively stable over time.

Conclusions: The results indicate that nurse-led multicomponent intervention was effective for improving physical and psychosocial function of the (pre)frail older adults living alone in Korea, suggesting that older adults can take proactive roles in conducting their daily life and managing their health. A strategy for disseminating widely sustainable nurse-led multicomponent interventions should be developed for community-dwelling frail elderly who live alone.

Keywords: Aged, Depression, Exercise, Frailty, Physical functional performance, Quasi-experimental study, Social support

* Correspondence: sjboo@ajou.ac.kr

Research Institute of Nursing Science, College of Nursing, Ajou University,

206 Worldcup-ro, Yeongtong-gu, 16499 Suwon, South Korea

(c) The Author(s). 2022 Open Access This article is licensed under a Creative Commons Attribution 4.0 International License, which permits use, sharing, adaptation, distribution and reproduction in any medium or format, as long as you give appropriate credit to the original author(s) and the source, provide a link to the Creative Commons licence, and indicate if changes were made. The images or other third party material in this article are included in the article's Creative Commons licence, unless indicated otherwise in a credit line to the material. If material is not included in the article's Creative Commons licence and your intended use is not permitted by statutory regulation or exceeds the permitted use, you will need to obtain permission directly from the copyright holder. To view a copy of this licence, visit http://creativecommons.org/licenses/by/4.0/ The Creative Commons Public Domain Dedication waiver (http://creativecommons.org/publicdomain/zero/1.0/) applies to the data made available in this article, unless otherwise stated in a credit line to the data. 


\section{Background}

The demographics of South Korea are rapidly shifting toward those of a super-aged population due to complex factors such as increased life expectancy, aging of the baby boomer generation, and declining fertility rates. The proportion of those aged 65 years or older rose from $7 \%$ to 2000 to $14 \%$ in 2017 and is expected to reach $20 \%$ by 2025 [1]. Moreover, the pace of population aging in Korea is faster than that of Western countries. While longevity can present opportunities for older adults, their families, and society, the extent of those opportunities depends largely on these individuals' health.

Aging can be accompanied by declines in physical and cognitive function, which negatively affect health and independence. Frailty has several approaches and operationalizations [2]. Recently, frailty is designated as a multidimensional concept, which encompasses losses in physical, psychological, and social functioning, and increases vulnerability to adverse health outcomes such as disability, hospitalization, or death [3-6]. At present, approximately $9.2-20.2 \%$ of community-dwelling older adults are categorized as frail in South Korea $[4,7,8]$. Importantly, pre-frailty, an early and reversible state before the onset of established frailty, has higher prevalence among community-dwelling older adults, ranging from 38.0 to $71.6 \%$ [8-10]. Given the rapid aging of the Korean population, efforts to slow down or prevent frailty and to keep older adults healthy and prolong their ability to live within the community should be an important public health priority. It can improve the quality of life among older adults and reduce heavy socioeconomic burdens.

Importantly, the prevalence of frailty is higher in vulnerable older adults of comparatively lower socioeconomic status (SES) $[7,10]$. In particular, socioeconomically vulnerable older adults living alone are more likely to face barriers in accessing health care resources and lack social support. Such vulnerabilities may lead to greater risks of frailty [11] and vice versa. In Korea, home-visiting nursing services in public health centers are designed to improve access to, and sustainability of, healthcare for socioeconomically vulnerable population. They are public health efforts at a national level by the Regional Public Health Act (Act No. 16,262, Article 11.5) [12]. The main target for the service is lower SES prefrail or frail older adults living alone.

Fortunately, frailty may be reversible with appropriate interventions [13]. Targeted approaches to preventing frailty, ideally before the onset of functional decline, have been proposed to decelerate the frailty process and maintain physical function among older adults. Since frailty is affected by multiple factors, it is highly appropriate to apply multidimensional interventions, targeting multiple contributing factors, than to address individual aspects. Several randomized controlled trials of such multidimensional interventions have reported beneficial effects on physical function, nutritional status, and depression among community-dwelling older people [1416]. Physical exercise programs, which are the basis of most interventions targeting frailty, have been shown to confer consistent favorable effects on physical function and muscle strength. Meanwhile, cognitive training and nutritional support play assistive roles in maintaining physical function in older adults [17].

In Korea, community-based nurse-led interventions have focused more on individual-based case management $[18,19]$ than social group approaches. However, psychosocial outcomes are important for older adults with frailty, who live alone, because their psychosocial status affects their physical energy and motivation for self-care [1]. According to general consensus, comprehensive community-based intervention is beneficial to prevent disability. It increases physical and social health in community-dwelling frail older adults [20], although less information is available on the comprehensive impact of a nurse-led multicomponent intervention on frail community-dwelling Korean older adults who live alone. In this study, we aimed to evaluate a nurse-led multicomponent intervention targeting community-dwelling older people living alone with an increased risk of frailty. More specifically, the aim of the present study was to evaluate the nurse-led intervention on the following outcomes: (a) frailty, (b) dynamic balance ability (Timed Up and Go Test [TUG]) results, and (c) handgrip strength. Evaluated psychosocial outcomes include (b) depression, (b) social activity, and (c) social support.

\section{Methods}

\section{Study design, setting, and sample}

A non-equivalent, controlled, pre-, post-, and follow-up test design was employed to identify the effectiveness of the multicomponent interventions for pre-frail or frail older adults of low SES who live alone. The study comprised a 12-week intervention and a 12-week follow-up period from May to November 2019. Samples for this study were selected from those who were enrolled in a public health center as a candidate for home-visiting nursing services, in a city near the capital city of Seoul, Korea. The services primarily focus on socioeconomically vulnerable populations, thus low SES prefrail or frail older adults in the community were considered as the candidates of this study.

Potential participants were identified through community screening. Eligible participants were (1) aged 65 years or older, (2) living alone, and (3) classified as prefrail or frail. Potential participants were approached by a trained research assistant and informed about the purpose of the research and its voluntary nature. Upon 
providing written informed consent, each participant underwent a baseline assessment. Frailty was screened using a comprehensive geriatric assessment questionnaire used in the Visiting Health Management Services of the Korean Ministry of Health and Welfare [12]. It consists of self-reported questionnaires and objective measures of complex mobility function. Self-reported items included questions about daily activities of living (five items: ability to use public transport, shop for small purchases, visit the bank, venture out, and attend counseling), mobility (five items: climbing stairs, standing from a chair, walking for $15 \mathrm{~min}$, history of falling, and fear of falling), nutritional status (five items: weight loss and body mass index, chewing or swallowing difficulties, and having a dry mouth), social activity (two items: number of outings per week and the frequency compared to the previous year), cognitive function (three items: forgetfulness, ability to make phone calls, and ability to recall past events), mood (five items), sensory function (one item: vision and hearing), and comorbidity. This information was collected through personal interviews conducted by a trained research assistant. The complex mobility function was measured using TUG.
Frailty levels were calculated based on the scoring guidelines. Two points were assigned to the presence of any comorbidity, and an abnormal TUG; one point was assigned to a negative answer to the other items, yielding a maximum possible score of 31 . Individuals were classified as robust if the frailty score was $0-3$, pre-frail for scores 4-12, and frail for scores 13-31. Based on these criteria, those with scores of 4 or more were included in this study [12].

The group assignment was based on the waiting list for home-visiting nursing services in the public center. According to the waiting list order, first the experimental group was assigned, and then the control group. A priori computation of sample size using $G^{*}$ Power version 3.1 revealed that 56 participants were required with an effect size (f) of 0.2 , an alpha value of 0.05 , and an actual power of 0.90 . A total of 138 participants completed the initial assessments (Fig. 1). Among them, eight participants failed to meet the inclusion criteria (frailty score $<4)$, so 130 participants were assigned to the experimental $(n=66)$ or the control $(n=64)$ group. Four participants in the experimental group withdrew from the study. Therefore, the final sample of 126 participants

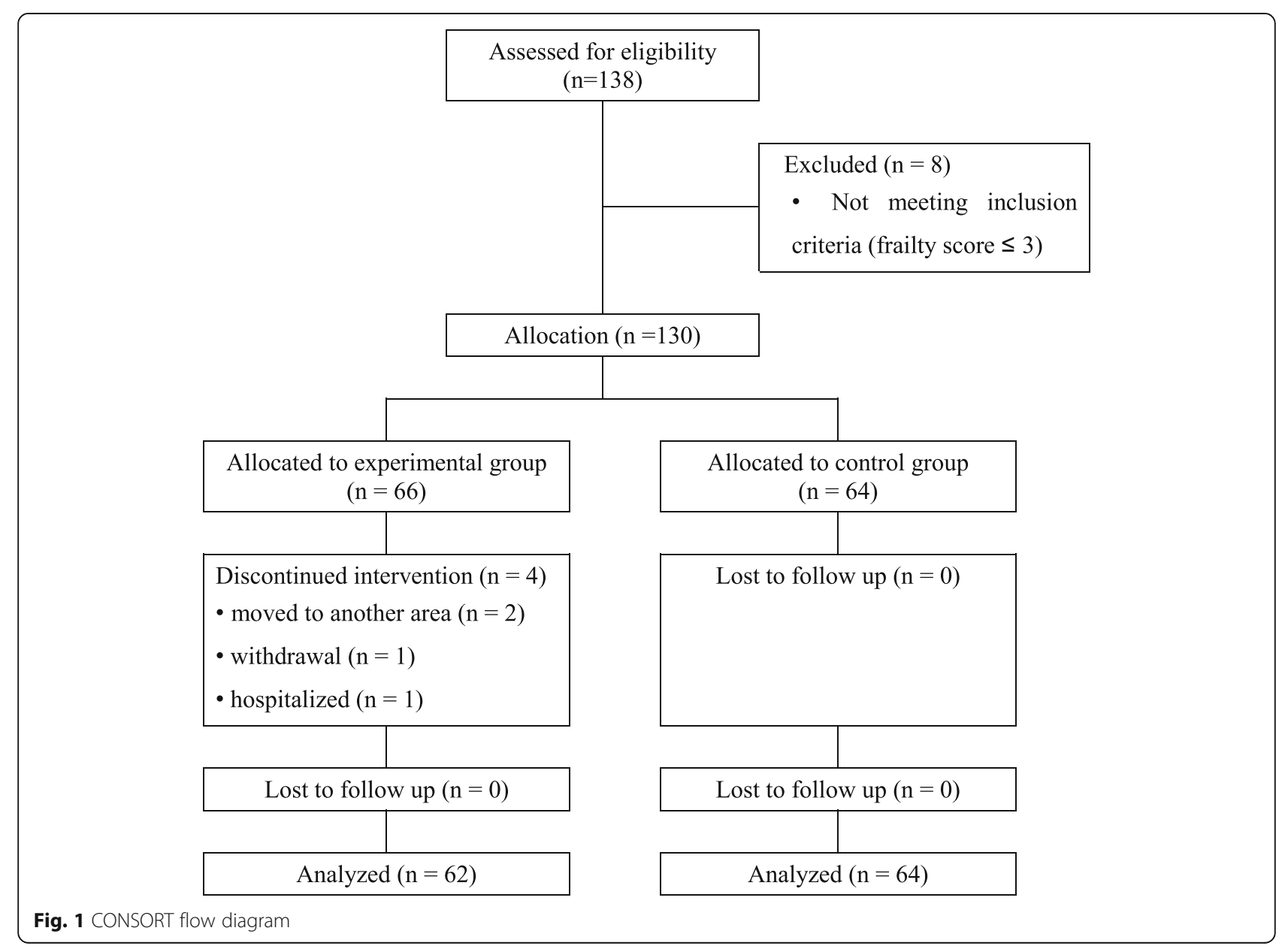


(62 in the experimental and 64 in the control group) was analyzed in this study.

\section{Intervention}

The 12-week multicomponent intervention for the experimental group was composed of exercise, cognitive training, and education for nutrition and disease management based on the multidimentional concept of frailty [2]. The intervention was conducted in accessible, attractive, and safe places, such as public health centers or senior centers to reduce the attrition rate. The intervention consisted of two 40-minute sessions once a week for 12 weeks. The first was a 40-minute group exercise session administered to approximately 10-15 participants by an exercise coach and trained exercise assistants. Each exercise session consisted of stretching (5 min), resistance exercises with elastic TheraBands (20 min), and aerobic movements (15 min) on rhythmic music selected by the participants to ensure a fun session. The intensity of the exercise was adjusted to suit the prefrail or frail elderly to reduce the follow-up loss. Each participant was trained for every activity according to their competence, allowing them to track their own exercise. They were closely monitored by the exercise coach and her assistants to prevent any injury. Resistance exercises focused on both the upper and lower extremities, emphasizing on muscles that are important for balance and gait control to prevent falls. The aerobic portion included stepping in standing positions or while sitting in a chair, as well as standing up from and sitting in a chair. Educational leaflets for each movement were distributed so that the participants could exercise at home even on days when they did not participate in the exercise class.

After the first exercise session, cognitive training session continued for another $40 \mathrm{~min}$. The second session included either calendar making or Cup Nanta, alternatively every other week, to improve cognitive function and sociality. These facilitated reminiscence and attention through art activities and folk music performances. The calendar-making program was operated using various materials; participants were encouraged to draw fun memories or special events of each month individually, and seasonal landscapes. The calendars were decorated with various, easily accessible materials, such as aluminum foil, old clothes, dried grains, coarse salt, cotton ball, etc. This process not only enabled the participants to reminisce about their meaningful everyday lives but also, and more crucially, helped them fulfill a desire for education that may have remained unfulfilled during their childhood. It simultaneously enhanced their concentration and sense of accomplishment.

Cup Nanta, a performance involving tapping cups on a desk according to a rhythm to achieve harmony, is designed to strengthen the fingers as well as to improve sociality and emotional bonds among the participants. The meticulous efforts taken by each member to produce a unified performance, by aligning the sequence and rhythm of each movement, and prevent errors, enhanced the overall performance.

Health education regarding nutrition and chronic disease management was provided once per month. Nutrition education or cooking classes focused on selecting healthy foods and convenient recipes. Physicians enhanced medication adherence and healthy lifestyle choices to the participants. They provided health education on therapeutic goals for managing chronic disease, blood glucose, blood pressure and self-management skills. In addition, therapeutic connections were formed between the participants and the medical doctors practicing in the participants' area of residence for direct treatment and consultation, to enable continuous treatment and monitoring after the program intervention. Healthy snacks were provided to reduce the risk of attrition. To ensure the validity of the study's results, the researchers who collected and analyzed the data did not participate in the program. They were blinded to the participants' group assignments.

\section{Measures}

Measures for the following outcome variables were completed three times: at pre-intervention, postintervention, and at the 12-week follow-up.

\section{Frailty}

We used 28-item frailty index to evaluate the effect of the intervention in this study [12]. It contains questions (containing five items each) regarding instrumental activities of daily living, physical functioning, nutritional status, and cognitive functioning. Participants were asked to answer yes or no to each question. Subsequently, the scores for all items were summed to indicate the level of frailty. Possible scores range from 0 to 31 , with higher scores indicating a higher likelihood of frailty.

\section{Timed Up and Go test (TUG)}

The complex mobility function was measured using TUG. Participants were asked to stand up from a standard armchair, walk $3 \mathrm{~m}$ straight, turn around, walk back, and sit down on the chair. The time from getting up from the seat to sitting again was measured in seconds.

\section{Handgrip strength}

The handgrip strength of the dominant hand was measured with a dynamometer (Tabita 6103) with participants standing upright, facing forward, with elbows fully extended and their feet shoulder-width apart. For each 
of the three measurement points (pre-intervention, postintervention, and at follow-up), handgrip strength was measured in kilograms twice, with a one-minute interval, and the scores were averaged for the analyses.

\section{Depression}

The 15-item Geriatric Depression Scale-Short Form Korean Version (GDSSF-K) measured depression [21, 22]. Participants were asked to rate their mood status on a yes or no scale. The level of depression was expressed as the average of all item scores, ranging from 0 to 15 . Higher scores represented a greater level of depressive mood. The reliability coefficient of the GDSSF-K in Kee's study was 0.88 [22], and 0.92 in this study.

\section{Social activity}

A five-item social activity scale developed in a sample of Korean older women living alone [23] was used to assess the levels of social activity in this study. Participants were asked to rate the frequency of their social activity for particular purposes, such as friend gatherings and economic or religious activities, on a scale of 0 (not at all) to 5 (every day). Total scores were calculated by averaging item scores, with higher scores indicating a greater frequency of social activities. Cronbach's alpha was 0.89 in the present study.

\section{Social support}

The 19-item Medical Outcomes Study Social Support Scale was used to measure the level of social support on a five-point Likert scale [24]. The total social support score was calculated based on the scoring guidelines, ranging from 0 to 100 . Higher scores indicate higher levels of social support. The scale was found to have good internal reliability at the time of its development. In this study, the internal reliability was 0.94 .

\section{Statistical analysis}

Data were analyzed using IBM SPSS software (version 23.0; IBM Corp., Armonk, NY, USA). The variables were screened for potential errors, missing data, and outliers. Assumptions were checked for every statistical analysis. Descriptive statistics were calculated for all variables. Bivariate analyses (i.e., t-tests, chi-square tests, and Fisher's exact test) were conducted to examine the homogeneity between the two groups. To evaluate the effect of the intervention over time, a mixed ANOVA (repeated measures) was used to compare the differences between the outcome measures of the two groups. Partial etasquared values were presented as a measure of effect size. A value of 0.01 indicates a small effect size, 0.06 indicates a moderate effect size, and 0.14 indicates a large effect size [25]. Differences were considered statistically significant at $p<0.05$.

\section{Results}

\section{Characteristics of participants}

A total of 126 older adults completed the study and were included in the analysis. Their mean age was $78.8( \pm$ $5.39)$ years, and $90.5 \%(n=115)$ of the participants were women. Approximately $30 \% \quad(n=37)$ perceived their health as good. The most common chronic disease among participants was hypertension (73.0\%), followed by arthritis (67.5\%) and diabetes (29.4\%) (Table 1). There were no statistically significant differences in the study variables by group at the baseline (Table 2).

\section{Effects of a nurse-led multicomponent intervention}

The effects of the multicomponent intervention are summarized in Table 3. Repeated measures analysis showed a significant group-by-time interaction on the levels of frailty, TUG, depression, social activities, and social support. A relatively greater improvement was

Table 1 Homogeneity of general characteristics ( $N=126)$

\begin{tabular}{|c|c|c|c|c|}
\hline \multirow[t]{2}{*}{ Variables } & Total & Experimental group $(n=62)$ & Control group $(n=64)$ & $p$ \\
\hline & \multicolumn{4}{|c|}{$\mathrm{n}(\%)$ or mean \pm SD } \\
\hline Sex (female) & $114(90.5)$ & $56(90.3)$ & $58(90.6)$ & 0.954 \\
\hline Age & $78.79 \pm 5.39$ & $79.56 \pm 5.50$ & $78.05 \pm 5.21$ & 0.114 \\
\hline Perceived good health & $37(29.4)$ & $22(35.5)$ & $15(23.4)$ & 0.172 \\
\hline Hypertension (yes) & $92(73.0)$ & $44(71.0)$ & $48(75.0)$ & 0.690 \\
\hline Diabetes (yes) & $37(29.4)$ & $13(21.0)$ & $24(37.5)$ & 0.051 \\
\hline Stroke (yes) & $5(4.0)$ & $3(4.8)$ & $2(3.1)$ & $0.677^{*}$ \\
\hline Heart disease (yes) & $12(9.5)$ & $5(8.1)$ & $7(10.9)$ & 0.763 \\
\hline Cancer(yes) & $12(9.5)$ & $6(9.7)$ & $6(9.4)$ & $1.000^{*}$ \\
\hline Arthritis(yes) & $85(67.5)$ & $37(59.7)$ & $48(75.0)$ & 0.087 \\
\hline Incontinence(yes) & $5(4.0)$ & $4(6.5)$ & $1(1.6)$ & $0.204^{*}$ \\
\hline
\end{tabular}

*Fisher exact test 
Table 2 Homogeneity of study variables ( $N=126)$

\begin{tabular}{|c|c|c|c|c|}
\hline \multirow[t]{2}{*}{ Variables } & Total & $\begin{array}{l}\text { Experimental group } \\
\qquad(n=62)\end{array}$ & $\begin{array}{l}\text { Control group } \\
(n=64)\end{array}$ & $p$ \\
\hline & \multicolumn{3}{|c|}{ Mean \pm SD } & \\
\hline Frailty & $10.23 \pm 3.67$ & $10.48 \pm 3.84$ & $9.98 \pm 3.52$ & 0.447 \\
\hline TUG (sec) & $10.06 \pm 5.95$ & $10.47 \pm 7.17$ & $10.45 \pm 7.69$ & 0.989 \\
\hline Handgrip strength (kg) & $19.60 \pm 5.29$ & $20.00 \pm 5.23$ & $19.22 \pm 5.36$ & 0.409 \\
\hline Depression & $6.21 \pm 3.18$ & $5.87 \pm 3.62$ & $6.53 \pm 2.67$ & 0.247 \\
\hline Social activities & $12.34 \pm 3.67$ & $12.97 \pm 3.45$ & $11.73 \pm 3.79$ & 0.059 \\
\hline Social support & $44.12 \pm 2.00$ & $48.11 \pm 22.82$ & $40.26 \pm 24.65$ & 0.066 \\
\hline
\end{tabular}

Note. TUG=Timed up \& go test

shown in the results reported from the pre-test to the post-test.

Post-hoc results showed a significant change in the levels of depression, social activity, and social support from pre-test to post-test (Fig. 2). The effects of the nurse-led multicomponent program in the experimental group were sustained over 12 weeks of follow-up.

\section{Discussion}

Using a non-equivalent, controlled, pre-, post-, and follow-up test design, this study evaluated the effects of a 12-week nurse-led multicomponent intervention for pre-frail or frail older adults aged 65 or above. This study found significant interactions between group (experiment or control) and times for all outcome variables except handgrip strength. In the experimental group, depression, social support, and social activity continuously improved from the first measurement during the 6month study period, while those in the control group were relatively stable over time.

Frailty includes impairments in physical, psychosocial, and cognitive functions. Thus, a multidimensional intervention that targets contributing factors of frailty could improve physical and psychosocial functions. Previous studies from other ethnic groups have reported that multicomponent interventions significantly improve participants' frailty levels compared to single interventions $[14,16]$. Regrettably, majority of the studies conducted in the Korean community settings have conducted a single intervention program such as exercise [26, 27], or

Table 3 Effects of intervention

\begin{tabular}{|c|c|c|c|c|c|c|c|c|c|c|}
\hline \multirow{2}{*}{$\begin{array}{l}\text { Variables } \\
\text { Frailty }\end{array}$} & \multirow[b]{2}{*}{ Exp. } & \multicolumn{2}{|c|}{ Pre-test } & \multicolumn{2}{|c|}{$\begin{array}{c}\text { Post-test } \\
\text { estimated mean (SE) }\end{array}$} & \multicolumn{2}{|c|}{ Follow-up test } & \multirow{2}{*}{$\begin{array}{l}\text { source } \\
G\end{array}$} & \multirow{2}{*}{$\begin{array}{l}\boldsymbol{p} \\
.459\end{array}$} & \multirow{2}{*}{$\begin{array}{l}\begin{array}{l}\text { Partial } \\
\text { Eta Squared }\end{array} \\
.004\end{array}$} \\
\hline & & 10.48 & $(0.47)$ & 8.53 & $(0.50)$ & 8.40 & $(0.52)$ & & & \\
\hline & Cont. & 9.98 & $(0.46)$ & 9.33 & $(0.49)$ & 9.52 & $(0.51)$ & $\mathrm{T}$ & $<.001$ & .223 \\
\hline & & & & & & & & $\mathrm{G}^{*} \mathrm{~T}$ & .009 & .073 \\
\hline \multirow[t]{3}{*}{ TUG (sec) } & Exp. & 10.47 & $(0.94)$ & 8.29 & $(0.94)$ & 8.16 & $(0.96)$ & G & .212 & .013 \\
\hline & Cont. & 10.45 & $(0.93)$ & 10.59 & $(0.92)$ & 10.83 & $(0.95)$ & $\mathrm{T}$ & $<.001$ & .191 \\
\hline & & & & & & & & $\mathrm{G}^{*} \mathrm{~T}$ & $<.001$ & .270 \\
\hline \multirow[t]{3}{*}{ Handgrip strength $(\mathrm{kg})$} & Exp. & 20.00 & $(0.67)$ & 20.35 & $(0.64)$ & 20.76 & (0.68) & G & .217 & .012 \\
\hline & Cont. & 19.22 & $(0.66)$ & 19.10 & $(0.63)$ & 19.48 & $(0.67)$ & $\mathrm{T}$ & .060 & .022 \\
\hline & & & & & & & & $\mathrm{G}^{*} \mathrm{~T}$ & .452 & .006 \\
\hline \multirow[t]{3}{*}{ Depression } & Exp. & 5.87 & $(0.40)$ & 4.19 & $(0.44)$ & 4.31 & $(0.44)$ & G & .012 & .050 \\
\hline & Cont. & 6.53 & $(0.40)$ & 5.91 & $(0.43)$ & 6.06 & $(0.43)$ & $\mathrm{T}$ & $<.001$ & .201 \\
\hline & & & & & & & & $\mathrm{G}^{*} \mathrm{~T}$ & .036 & .052 \\
\hline \multirow[t]{3}{*}{ Social activities } & Exp. & 12.97 & $(0.46)$ & 14.10 & $(0.46)$ & 14.06 & $(0.50)$ & G & .002 & .076 \\
\hline & Cont. & 11.73 & $(0.45)$ & 11.81 & $(0.46)$ & 11.56 & $(0.49)$ & $\mathrm{T}$ & .006 & .080 \\
\hline & & & & & & & & $\mathrm{G}^{*} \mathrm{~T}$ & .007 & .077 \\
\hline \multirow[t]{3}{*}{ Social support } & Exp. & 48.11 & (3.02) & 53.64 & $(2.98)$ & 55.00 & $(2.99)$ & G & .005 & .061 \\
\hline & Cont. & 40.26 & (2.97) & 41.19 & $(2.94)$ & 40.75 & $(2.95)$ & $\mathrm{T}$ & .001 & .114 \\
\hline & & & & & & & & $\mathrm{G}^{*} \mathrm{~T}$ & .012 & .070 \\
\hline
\end{tabular}



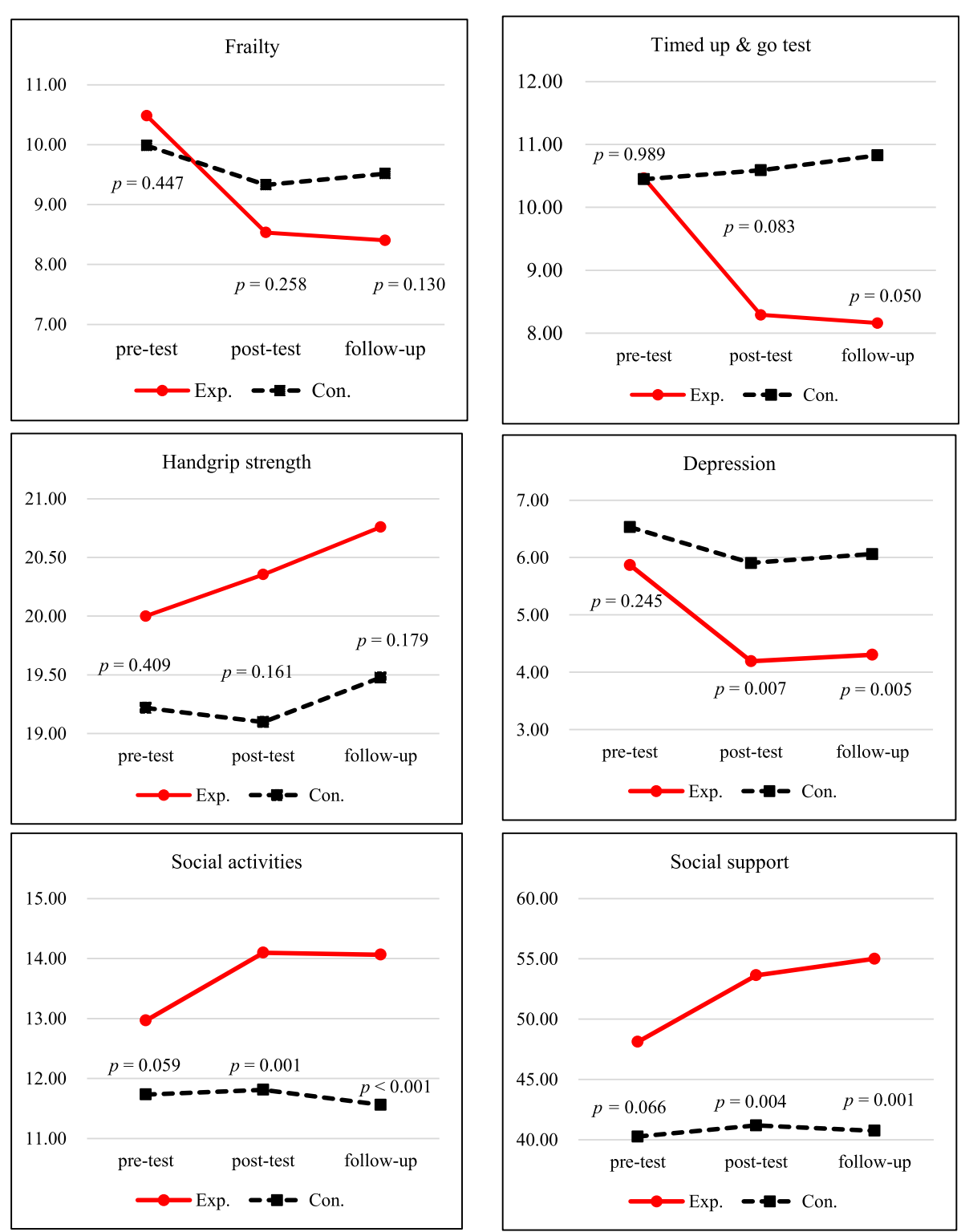

Fig. 2 Effects of nurse-led multicomponent intervention

have investigated the effects of an intervention for prefrail or frail adults merely on the basis of physical or psychological aspects [18, 26-28]. The studies did not consider or measure the impacts of socialization in individuals participating in the interventions. However, psychosocial components make an impact on physical energy and self-care motivation, which is particularly crucial for frail older adults who live alone [15].

Prefrail or frail older adults generally have low levels of social involvement, increasing their frailty [29, 30]. People living alone, especially, have a lower availability of personal assistance and greater social vulnerability [31]. Therefore, this study was conducted with an assumption that multicomponent intervention through the well-designed community social networks would be a solution to improve the health status of prefrail or frail older adults by activating their life pattern.

To facilitate socialization in this study, a small group rather than an individual-based approach was used. Levels of social activity and social support were measured to identify whether changes in the participants' daily lives would produce improvements in the levels of frailty over the study period. Upon the intervention completion, a statistically significant improvement was found in the social activity and social support. The effects were sustained during the follow-up periods, which may lead to improvements in physical and psychological health, such as depression and frailty. We could explain 
that such positive changes in physical and psychological health, found in the experimental group, might be in part due to the intentional expansion of their daily activity spectrum through their regular participation in the comprehensive program across the 12 weeks, as they had previously lived alone and engaged in limited social activities. Therefore, our results contradict those of a previous study [32] that determined evidence regarding the effect of resident participation on health is unclear. The research was based on a "passive view" [33] that considers participation to be a goal in and of itself, rather than considering participation as a means to fulfill the goal of changing health behavior and improving physical and psychological health.

Minimizing attrition is crucial in intervention studies because follow-up loss could affect the strength of a study's findings. The attrition rate of this study is relatively low compared to the previous studies of older adults. Strategies used to minimize attrition includes the collection of detailed contact information, encouragement of participation with postcards and calls, incentives for study participations, and enhancement of social support. As program factors, the exercise session added an element of fun by using rhythmic music selected by the participants, and the intensity of the exercises was adjusted based on one's exercise capacity. Furthermore, connections were made between the participants and the medical doctors practicing in the participants' area of residence for direct treatment and consultation to enable continuous treatment and monitoring after the intervention, rather than concluding with a single education session. This design was intended to prevent loss to followups. Our findings suggest that consistent and ongoing engagement in the program has induced positive and statistically significant changes in outcome variables in the experimental group as compared to the control group.

This study has several limitations. First, a nonequivalent control group study was used because it was difficult to conduct randomization for ethical or practical reasons. Participants were selected from the waiting list of the home-visiting nursing service of a public health center. Given that the service is designed for a vulnerable population as public health efforts at the national level, the experimental group was created first according to the waiting list order. Even though homogeneity tests revealed no significant differences according to the group's general characteristics and outcome variables pre-intervention, further randomized studies need to be considered to control for the effects of unexpected confounding variables on the outcome variables, or selection bias. Second, most of the participants in this study were women. The incidence, determinant, and trajectory of frailty as well as life expectancy differ by gender [34-36]. Gender-specific intervention strategies need to be developed, and future studies should oversample men to ensure parity and ability for gender specific analyses. Additionally, this study involved a 12-week (once per week for 12 weeks) intervention, and a follow-up measurement 12 weeks after the intervention. Participants may show positive changes in certain outcome variables. However, the intervention's duration and intensity may not have been sufficient to modify physical functions, such as handgrip strength and frailty. Future studies with longer interventions and higher frequent measurements are required to draw greater empirical conclusions regarding the outcome variables.

\section{Conclusions}

Given that Korea is rapidly aging, the proportion of frail and older adults living alone will inevitably increase. Therefore, it is crucial to assist older adults in living safely and independently in the community for as long as possible. This study showed that nurse-led multicomponent intervention was effective for prefrail and frail older adults living alone in Korea, presenting the possibility of proactive management regarding their health and leading their daily life. Therefore, a strategy for disseminating widely sustainable nurse-led multicomponent interventions should be developed for communitydwelling frail elderly who live alone.

\section{Abbreviations}

SES: socioeconomic status; TUG: Timed Up and Go Test; GDSSF-K: Geriatric Depression Scale-Short Form Korean Version

\section{Acknowledgements}

We express our sincere gratitude to all the participants. We also thank Sunhee Yoo for her support with data collection.

\section{Authors' contributions}

Conceptualization: MS, SB. Data curation: SB. Formal analysis: SB. Funding acquisition: SB. Investigation: MS, SB. Project administration: SB. Writing of the original draft: MS, SB. Writing and/or reviewing and editing: MS, SB. The author(s) read and approved the final manuscript.

\section{Funding}

This work was supported by the research fund of Ajou University College of Nursing (M-2019-C0460-00034).

\section{Availability of data and materials \\ The datasets used and/or analyzed during the current study are available from the corresponding author on reasonable request.}

\section{Declarations}

Ethics approval and consent to participate

For this study, approval from the Institutional Ethics Committee was obtained (AJIRB-SBR-SUR-19-082). All participants provided informed consent, and the study was conducted per the Declaration of Helsinki. Considering the ethical perspectives, various materials (TheraBands and educational booklets) necessary for health management were provided to those in the control group, along with one session of education at the participants' homes by home-visit nurses in the public health center at the beginning of the study. 


\section{Consent for publication}

Not applicable.

\section{Competing interests}

The authors declare that they have no competing interests.

Received: 13 October 2021 Accepted: 29 December 2021

Published online: 17 January 2022

\section{References}

1. Statistics Korea. Estimated Population by Age Group. 2020. http://kostat.go. kr. Accessed 13 July 2021

2. Van der Elst MCJ, Schoenmakers B, Op het Veld LPM, De Roeck EE, Van der Vorst A, Kempen IMJG, et al. Concordances and differences between a unidimensional and multidimensional assessment of frailty: a cross-sectional study. BMC Geriatr. 2019; 19: 346. doi:https://doi.org/10.1186/s12877-019-1369-7

3. Gobbens RJ, Luijkx KG, Wijnen-Sponselee MT, Schols JMGA. In search of an integral conceptual definition of frailty: opinions of experts. J Am Med Dir Assoc. 2010; 11(5): p. 338-343. doi:https://doi.org/10.1016/j.jamda.2009.09.015

4. Jung HW, Kim SW, Ahn S, Lim JY, Han JW, Kim TH, et al. Prevalence and outcomes of frailty in Korean elderly population: comparisons of a multidimensional frailty index with two phenotype models. PloS One. 2014; 9(2):e87958. doi:https://doi.org/10.1371/journal.pone.0087958.

5. Ida S, Kaneko R, Imataka K, Murata K. Relationship between frailty and mortality, hospitalization, and cardiovascular diseases in diabetes: a systematic review and meta-analysis. Cardiovasc Diabetol. 2019;18(1):81. doi: https://doi.org/10.1186/s12933-019-0885-2.

6. Chao CT, Wang J, Chien KL, Cohort of Geriatric Nephrology in NTUH (COGENT) study group. Both pre-frailty and frailty increase healthcare utilization and adverse health outcomes in patients with type 2 diabetes mellitus. Cardiovasc Diabetol. 2018;17(1):130. doi:https://doi.org/10.1186/s12 933-018-0772-2

7. Ko Y, Choi K. Prevalence of frailty and associated factors in Korean older women: The KLoSA study. J Women Aging. 2017;29(1):15-25. doi:https://doi. org/10.1080/08952841.2015.1018069.

8. Chon D, Lee Y, Kim J, Lee KE. The association between frequency of social contact and frailty in older people: Korean Frailty and Aging Cohort Study (KFAC S). J Korean Med Sci. 2018; 33:e332. doi.https:/doi.org/10.3346/jkms.2018.33.e332.

9. Collard RM, Boter H, Schoevers RA, Oude Voshaar RC. Prevalence of frailty in community-dwelling older persons: a systematic review. J Am Geriatr Soc. 2012;60(8):1487-1492. doi:https://doi.org/10.1111/j.1532-5415.2012.04054.x.

10. Siriwardhana DD, Hardoon S, Rait G, Weerasinghe MC, Walters KR. Prevalence of frailty and prefrailty among community-dwelling older adults in low-income and middle-income countries: a systematic review and meta-analysis. BMJ Open. 2018:8:e018195. doi:https://doi.org/10.1136/bmjopen-2017-018195.

11. Franse CB, van Grieken A, Qin L, Melis RJF, Rietjens JAC, Raat H. Socioeconomic inequalities in frailty and frailty components among community-dwelling older citizens. PLoS One. 2017;12(11):e0187946. doi: https://doi.org/10.1371/journal.pone.0187946.

12. Ministry of Health and Welfare Affairs. Guidebook for 2019 community integrated health promotion program: Visiting health care. Sejong: Ministry of Health and Welfare. 2019. https://www.khealth.or.kr/kps/publish/ view?menuld=MENU00890\&page no=B2017003\&pageNum $=1 \&$ siteld $=$ \&srch_text=\%EB\%B0\%A9\%EB\%AC\%B8\%EA\%B1\%B4\%EA\%B0\%95\&srch_cate= \&srch_type=ALL\&str_clft_cd_list=\&str_clft_cd_type_list=\&board_idx=10220. Accessed 10 July 2021.

13. Gill TM, Gahbauer EA, Allore HG, Han L. Transitions between frailty states among community-living older persons. Arch Intern Med. 2006;166(4):418423. https://doi.org/10.1001/archinte.166.4.418.

14. Dedeyne L, Deschodt M, Verschueren S, Tournoy J, Gielen E. Effects of multi-domain interventions in (pre)frail elderly on frailty, functional, and cognitive status: a systematic review. Clin Interv Aging. 2017;12:873-896. doi:https://doi.org/10.2147/CIA.S130794.

15. Wong AKC, Wong FKY. The psychological impact of a nurse-led proactive self-care program on independent, non-frail community-dwelling older adults: A randomized controlled trial. Int J Nurs Stud. 2020;110:103724. doi: https://doi.org/10.1016/j.jinurstu.2020.103724.

16. Yu R, Tong C, Ho F, Woo J. Effects of a multicomponent frailty prevention program in prefrail community-dwelling older persons: a randomized controlled trial. J Am Med Dir Assoc. 2020;21(2):294.e1-294.e10. doi:https:// doi.org/10.1016/j.jamda.2019.08.024.
17. Marx W, Lane M, Hockey M, Aslam H, Berk M, Walder K, et al. Diet and depression: exploring the biological mechanisms of action. Mol Psychiatry. 2021;26:134-150. doi:https://doi.org/10.1038/s41380-020-00925-x

18. Yang S-O, Kwon MS, Choi Y-J, Lee S-H. The effects of a case management program of customized home visiting health service for clients with arthritis. J Korean Acad Commun Health Nurs. 2011;22(2):151-161. doi:https://doi. org/10.12799/jkachn.2011.22.2.151.

19. Jang HS. The effect of case management for clients with hypertension in home visiting health services. J Korean Public Health Nurs. 2014;28(2):258269. doi:https://doi.org/10.5932/JKPHN.2014.28.2.258.

20. Kojima G, Liljas AEM, Iliffe S. Frailty syndrome: implications and challenges for health care policy. Risk Manag Healthc Policy. 2019;12:23-30. doi:https:// doi.org/10.2147/RMHP.S168750.

21. Yesavage $J A$, Brink TL, Rose $T L$, Lum $O$, Huang $V$, Adey $M$, et al. Development and validation of a geriatric depression screening scale: a preliminary report. J Psychiatr Res. 1982-1983;17(1):37-49. doi:https://doi. org/10.1016/0022-3956(82)90033-4.

22. Kee B-S. A preliminary study for the standardization of geriatric depression scale short form-Korea version. J Korean Neuropsychiatr Assoc. 1996:35(2):298-307.

23. Kang $\mathrm{H}-J$. Social activity and satisfaction of life in female elders living alone in rural area. Korean J Soc Welf Res. 2009:1-26.

24. Sherbourne CD, Stewart AL. The MOS social support survey. Soc Sci Med. 1991;32(6):705-714. doi:https://doi.org/10.1016/0277-9536(91)90150-b.

25. Cohen J. Statistical Power Analysis for the Behavioral Sciences. 2nd ed. New Jersey: Hillsdale; 1988.

26. Song MS, Boo S. The effect of an exercise program for preventing urinary incontinence among community-dwelling elderly females living alone. J Korean Public Health Nurs. 2016;30(2):247-258. doi:https://doi.org/10.5932/ JKPHN.2016.30.2.247

27. Kim S, Lee EJ, Kim HO. Effects of a physical exercise program on physiological, psychological, and physical function of older adults in rural areas. Int J Environ Res Public Health. 2021;18(16):8487. doi:https://doi.org/1 0.3390/ijerph18168487.

28. Jang IY, Jung HW, Park H, Lee CK, Yu SS, Lee YS, et al. A multicomponent frailty intervention for socioeconomically vulnerable older adults: a designed-delay study. Clin Interv Aging. 2018;13:1799-1814. doi:https://doi. org/10.2147/CIA.S177018.

29. Jeong HJ, Yoon SH. The influencing factors on the ego integrity of elderly living alone. J Korean Acad Soc Nurs Educ. 2015;21(4):499-508. doi:https:// doi.org/10.5977/jkasne.2015.21.4.499.

30. Park JS, Oh YJ. Health promotion behavior, perceived health status, social participation and empowerment in frail elderly receiving home visiting services. J Korean Public Health Nurs. 2017;31(2):244-256. doi:https://doi. org/10.5932/JKPHN.2017.31.2.244

31. Gardner PJ. Natural neighborhood networks — important social networks in the lives of older adults aging in place. J Aging Stud. 2011;25(3):263-71. doi:https://doi.org/10.1016/j.jaging.2011.03.007

32. Evans $D$, Pilkington $P$, McEachran M. Rhetoric or reality? A systematic review of the impact of participatory approaches by UK public health units on health and social outcomes. J Public Health (Oxf). 2010;32(3):418-426. doi: https://doi.org/10.1093/pubmed/fdq014.

33. Hong N-S, Kim K-Y, Lee K-S, Kim M-H, Kim E-H, Park M-A, et al. Effects and challenges of community-based participatory health project of Gyeongsangbuk-do province in Korea. J Health Info Stat. 2020;45(2):200207. doi:https://doi.org/10.21032/jhis.2020.45.2.200

34. Gordon EH, Peel NM, Samanta MO, Theou SE, Howlett RE, Hubbard RE. Sex differences in frailty: A systematic review and meta-analysis. Exp Gerontol. 2017;89: 30-40. doi:https://doi.org/10.1016/j.exger.2016.12.021.

35. Shinkai S, Yoshida H, Taniguchi Y, Murayama H, Nishi M, Amano H, et al. Public health approach to preventing frailty in the community and its effect on healthy aging in Japan. Geriatr Gerontol Int. 2016; Suppl 1:87-97. https:// doi.org/10.1111/ggi.12726

36. Kontis V, Bennett JE, Mathers CD, Li G, Foreman K, Ezzati M. Future life expectancy in 35 industrialised countries: projections with a Bayesian model ensemble. Lancet. 2017;389(10076):1323-1335. doi:https://doi.org/10.1016/ S0140-6736(16)32381-9

\section{Publisher's Note}

Springer Nature remains neutral with regard to jurisdictional claims in published maps and institutional affiliations. 